ARTICLE

DOI: $10.1038 / \mathrm{s} 41467-018-06016-4$

\title{
Stereoselective oxidative glycosylation of anomeric nucleophiles with alcohols and carboxylic acids
}

Tianyi Yang ${ }^{1}$, Feng Zhu $^{1} \&$ Maciej A. Walczak (iD ${ }^{1}$

Oligosaccharides, one of the most abundant biopolymers, are involved in numerous biological processes. Although many efforts have been put in preparative carbohydrate chemistry, achieving optimal anomeric and regioselectivities remains challenging. Herein we describe an oxidative glycosylation method between anomeric stannanes and oxygen nucleophiles resulting in the formation of a $\mathrm{C}-\mathrm{O}$ bond with consistently high anomeric control for glycosyl donors bearing a free C2-hydroxyl group. These reactions are promoted by hypervalent iodine reagents with catalytic or stoichiometric amounts of $\mathrm{Cu}$ or $\mathrm{Zn}$ salts. The generality of this transformation is demonstrated in 42 examples. Mechanistic studies indicate that the oxidative glycosylation is initiated by the hydroxyl-guided delivery of the hypervalent iodine and tosylate into the anomeric position, and results in excellent 1,2-trans selectivity. The unique mechanistic paradigm, high selectivities, and mild reaction conditions make this method suitable for the synthesis of oligosaccharides and for integration with other methodologies such as automated synthesis.

\footnotetext{
${ }^{1}$ Department of Chemistry and Biochemistry, University of Colorado Boulder, Boulder, CO 80309, USA. These authors contributed equally: Tianyi Yang, Feng Zhu. Correspondence and requests for materials should be addressed to M.A.W. (email: maciej.walczak@colorado.edu)
} 
S accharides are essential biomolecules that, due to their vast chemical diversity, fulfill a wide scope of physiological functions ranging from the maintenance and survival of cells to the storage and supply of energy ${ }^{1}$. The inherent structural complexity of carbohydrates enables them to interact with myriad biological receptors and the efforts to decipher the sugar code has recently received considerable attention ${ }^{2}$. One strategy to understand the role of saccharides in living organisms is to prepare well-defined glycans that, when used as probes, provide a meaningful output that can be correlated with the structure of the sugar. An approach that capitalizes on chemical synthesis is characterized by broad versatility and scalability as any desired modifications are available by chemical means. However, a great majority of methods that form the glycosidic bond often relies on displacement reactions at the $\mathrm{C} 1$ position making the control of anomeric configuration a daunting $\operatorname{task}^{3}$. The introduction of protective groups is often deemed necessary in order to regioselectively install a new $\mathrm{C}-\mathrm{O}$ linkage between two saccharide groups, despite obvious limitations such as suboptimal stepeconomy and synthetic efficiency. Without enzymatic catalysis, direct glycosylations engaging glycosyl donors bearing free hydroxyl groups are known for their low yields and poor selectivities ${ }^{4,5}$. Furthermore, stereoselective chemical glycosylations that are characterized by high anomeric selectivities across a broad range of substrates often rely on neighboring group participation, transient protection, or the unique scaffold features of the glycosyl donor (e.g., 1,2-anhydrosugars also known as glycal epoxides) ${ }^{6}$. A conceptually orthogonal approach that addresses the problem of variable anomeric selectivities requires the use of glycosyl donors with free hydroxyl groups that can act as a directing group thus eliminating the need for exhaustive protecting group manipulations. Herein, we report one-pot oxidative $O$-glycosylation of partially protected glycosyl donors that proceeds under mild reaction conditions without compromising yield and with exclusive anomeric selectivities.

Commonly employed strategies for stereoselective $O$-glycosylation are outlined in Fig. 1. Of these, the most widely applied methods capitalize on reactions of glycosyl donors in which the C2 position is capped with a carbonyl-based participating group (e.g., OAc, OBz, NPhth) $)^{7-10}$. For example, activation of 2-O-acyl thioglycoside with an oxidant and triflate salt leads to the formation of the dioxolenium ion intermediate $\mathbf{4}$ which is quenched with an alcohol to provide glycoside $\mathbf{1}$ in high 1,2-trans selectivity (Fig. 1a $)^{11}$. Other approaches based on a locked bicyclic conformation utilize acetal ${ }^{12}$, carbonate $^{13}$, or carbamate ${ }^{14}$ groups introduced into the pyranose scaffold to amplify the differences of the energy barriers between two transition states ${ }^{15}$. Ring opening reactions of glycal epoxides in the presence of Lewis acid catalysts or bases provided a more direct solution to 1,2-trans configured glycosides (Fig. 1b) ${ }^{16-19}$. Primary alcohols and sterically unhindered secondary alcohols found the most success with this method, while some demanding glycosyl acceptors depend more on the pre-activation of hydroxyl group (e.g., as a stannyl ether) and the compatible Lewis acid to achieve good yield and stereoselectivity $17,20,21$.

The problem of anomeric selectivities is even more pronounced when encountered in reactions with partially protected or free saccharides. In addition to the control of the anomeric configuration, regioselectivity becomes a critical consideration. Unlike reactions of partially protected glycosyl acceptors that can be manipulated using catalytic or stoichiometric conditions, only isolated examples of chemical glycosylations have been reported
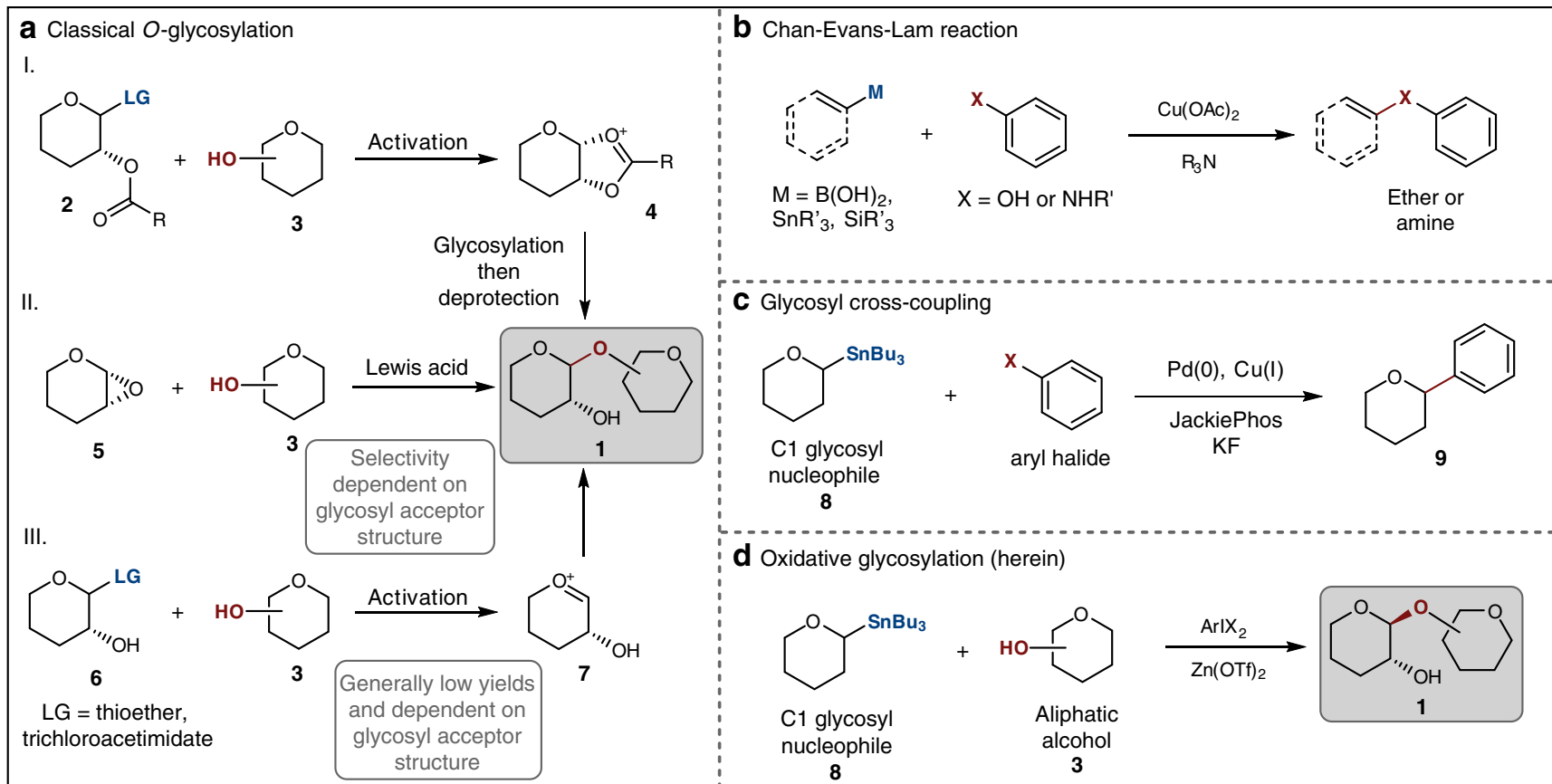

Fig. 1 Strategies for O-glycosylation and the stereochemical outcome. a (i) Neighboring group participation (2-O-acyl glycosyl donor 2) directed stereoselective glycosylation. Formation of dioxolenium cation $\mathbf{4}$ leads to 1,2-trans product using this method. LG leaving group (halogen, acetimidate, sulfide, etc.). (ii) O-glycosylation via a Lewis acid-catalyzed ring opening of a glycal epoxide. The epoxide is typically prepared from the oxidation of glycal and undergoes ring opening, resulting in a 2-hydroxy 1,2-trans glycoside. (iii) O-glycosylation with glycosyl donors bearing free hydroxyl group(s). The yield of this method is diminished due to the self-conjugation, and a mixture of anomers is usually obtained. LG leaving group (halogen, acetimidate, sulfide, etc.). $\mathbf{b}$ Etherification by the Chan-Evans-Lam reaction. Two nucleophiles are joined together to form an aryl ether. $M$ main group metalloids (boronic acids, boronates, stannanes, silanes, and siloxanes). c A stereoselective C-glycosylation with a C1 nucleophile catalyzed by a transition metal catalyst. d A stereoselective $\mathrm{O}$-glycosylation with glycosyl donors bearing free a hydroxyl group catalyzed by zinc triflate 


\section{Table 1 Identification and optimization of anomeric acylation}

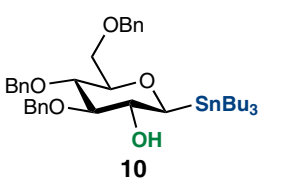

$$
\begin{aligned}
& \text { Cu source, } \mathrm{Phl}(\mathrm{OAc})_{2}, \\
& \mathrm{KF}(4 \text { equiv }), 4 \AA \mathrm{MS}, \\
& \text { solvent }(0.025 \mathrm{M})
\end{aligned}
$$

\begin{tabular}{lllll}
\hline Entry & Cu source & Phl(OAc) & Solvent & Yielda $^{\mathbf{2}}$ \\
\hline 1 & $\mathrm{CuCl}$ & 2 equiv & $\mathrm{PhMe}$ & $45 \%$ \\
2 & $\mathrm{CuBr}$ & 2 equiv & $\mathrm{PhMe}$ & $\mathrm{ND}$ \\
3 & $\mathrm{Cul}$ & 2 equiv & $\mathrm{PhMe}$ & $\mathrm{ND}$ \\
4 & $\mathrm{CuCl}$ & 2 equiv & dioxane & $56 \%$ \\
5 & $\mathrm{CuCl}$ & 2 equiv & PhMe-dioxane & $77 \%$ \\
$6^{\mathrm{b}}$ & $\mathrm{CuCl}$ & 2 equiv & $\mathrm{PhMe}-$ dioxane & $58 \%$ \\
7 & $\mathrm{CuCl}$ & 2 equiv & $\mathrm{THF}$ & $\mathrm{ND}$ \\
8 & $\mathrm{CuCl}$ & 2 equiv & $\left(\mathrm{CH}{ }_{2} \mathrm{Cl}\right)_{2}$ & $\mathrm{ND}$ \\
\hline
\end{tabular}

Reagents and conditions: Cu source (2 equiv), PIDA (2 equiv), KF (4 equiv)

ND not detected

alsolated yield of analytically pure $\mathbf{1 1}$

Reaction run at $0.05 \mathrm{M}$ concentration of 10

engaging glycosyl donors with free hydroxyl group(s) (Fig. 1a) $4,5,22$. The use of glycosyl donors with conventional leaving groups such as in Schmidt donors and thioglycosides afforded a mixture of anomers although the hydroxyl group in the glycosyl donors often shows reduced reactivity that enables the site-selective control of the glycosylation event. Nevertheless, in glycosylation with donors such as anomeric dithiocarbamate and phosphate, it has been reported that free hydroxyl group can be tolerated without compromising the yield and stereoselectivity ${ }^{23-25}$. Somewhat related, although mechanistically distinct, is the photoredox-based approach with a boronic acid as an additive with little improvement in terms of stereoselectivity ${ }^{26}$. More recently, temporal boron-protection of thioglycoside donors with stoichiometric amount of dialkylboryl was shown to yield high 1,2 -trans anomers ${ }^{27}$. Other strategies for the chemical O-glycosylation of unprotected glycosyl donors include chemoenzymatic synthesis, solid-phase approach, and catalyst-induced methods ${ }^{28,29}$. However, despite clear benefits of the approaches that rely on minimal protective group manipulations, previous attempts can seldom be applied to a broad substrate selection for regioselective installation of the glycosidic bond. Because of these inherent limitations, an approach that capitalizes on reactions with anomeric nucleophile can offer a promising solution. This proposal is based on the observation that under oxidative conditions nucleophiles such as alcohols, phenols, and amines can be coupled with boronic acids or stannanes forming a new $\mathrm{C}-\mathrm{O}$ and $\mathrm{C}-\mathrm{N}$ bond (the Chan-Evans-Lam reaction, Fig. 1d) ${ }^{30-32}$. However, the application of the oxidative coupling to chemical glycosylation is challenged by a limited knowledge about reactions of $\mathrm{C}\left(s p^{3}\right)$ nucleophiles, as well as the unpredictability of stereochemical course in the $\mathrm{C}-\mathrm{O}$ bond-forming step ${ }^{33-36}$. Phenols and amines with suitable nucleophilicity are optimal substrates for the coupling with $\mathrm{C}\left(s p^{2}\right)$ partners and only isolated examples of crosscoupling of trifluoroborates with aliphatic alcohols have been reported 37,38 .

We recently described a mechanistically unique method for the $C$-glycosylation of glycosyl stannane donors bearing free hydroxyl groups that features a remarkably high stereospecificity and minimal dependence on directing groups and carbohydrate scaffold $^{39,40}$. C1 stannanes can be prepared for a range of monoand oligosaccharides and retain their configurational stability after exposure to water, air, and even elevated temperatures.

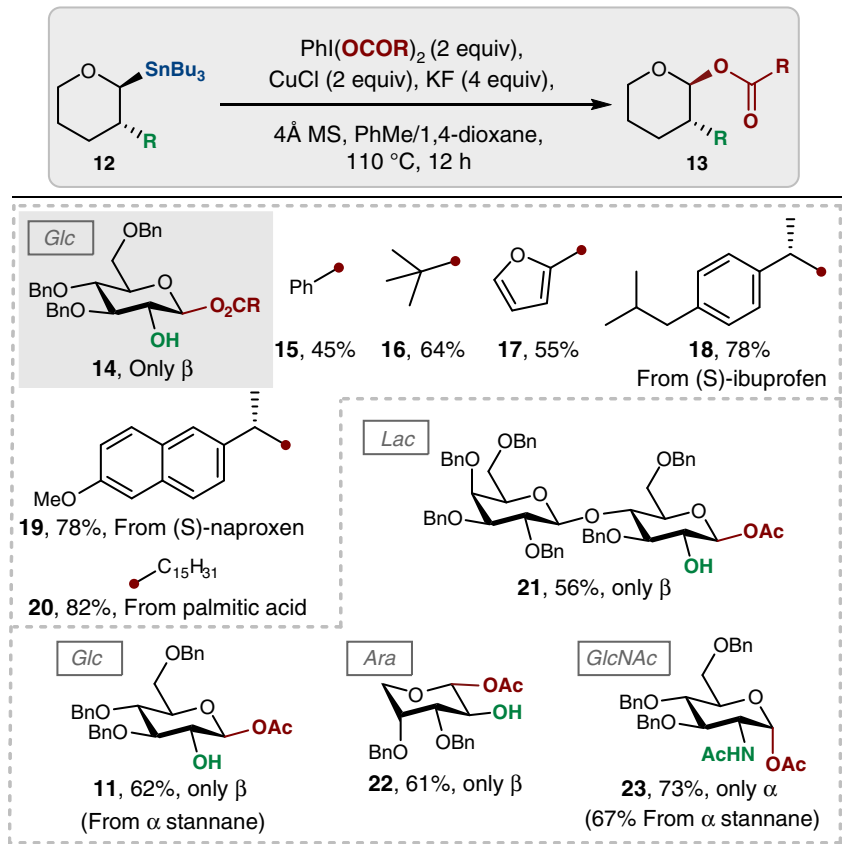

Fig. 2 Scope of oxidative acylation of glycosyl C1 stannanes. In all cases, the formation of only one anomer was observed (based on the ${ }^{1} \mathrm{H}$ NMR analysis of the unpurified reaction mixtures). Phenyliodonium dicarboxylates were obtained from iodosobenzene diacetate and the corresponding carboxylic acid

Based on this result, here we show a conceptually distinct approach for stereoselective $O$-glycosylation as depicted in Fig. 1d. We hypothesized that under oxidative conditions anomeric stannanes might undergo transmetalation to copper or a ligand transfer to other oxidants such as hypervalent iodine ${ }^{41,42}$ followed by reductive elimination to establish a new glycosidic bond. In this mechanistic paradigm, the $\mathrm{C}-\mathrm{O}$ bond-forming step could proceed inter- or intramolecularly, depending on the nature of the oxidant and the nucleophile used. However, the ability to access this type of glycosyl donors opens the opportunity to perform these reactions with partially protected glycosyl donors.

\section{Results}

Optimization of reaction conditions. To test our hypothesis, we first set out to identify conditions which could promote the union of alcohols with $\mathrm{C} 1$ nucleophiles without concomitant oxidation of the hydroxyl groups. Inspired by the prior work by $\mathrm{Gin}^{43}$, we investigated reactions of anomeric stannanes in the presence of a stoichiometric oxidant ( $\left.\mathrm{PhI}(\mathrm{OAc})_{2}, \mathrm{PIDA}\right)$, a copper catalyst, and $\mathrm{KF}$ as an additive facilitating the transmetalation step (Table 1). D-glucose nucleophile $\mathbf{1 0}$ was selected as a model system to gain a better understanding of the reactivity of anomeric stannanes under these conditions. We found that $\mathbf{1 0}$ could be converted into anomeric acetate $\mathbf{1 1}$ with exclusive 1,2-trans selectivity when treated with the oxidant (entry 1). Further optimizations revealed the unique role of $\mathrm{CuCl}$ and other $\mathrm{Cu}(\mathrm{I})$ salts were ineffective in promoting oxidation of $\mathbf{1 0}$ (entries 2 and 3). We established that 1,4-dioxane (entry 4) or a 1:1 mixture of PhMe and 1,4-dioxane (entries 5 and 6) resulted in the best isolated yield whereas THF or chlorinated solvents suppressed the acylation reaction (entries 7 and 8 ).

Because the iodine oxidant is the source of the acetate group, we next wondered if other carboxylate groups could be transferred into the anomeric position (Fig. 2). We found that 


\section{Table 2 Optimization of oxidative glycosylation with} anomeric nucleophiles
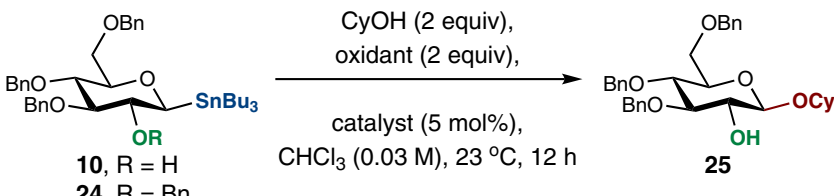

24, $\mathrm{R}=\mathrm{Bn}$

\begin{tabular}{|c|c|c|c|c|c|}
\hline Entry & Substrate & Oxidant & Catalyst & Yield $^{a}$ & $d r^{b}$ \\
\hline 1 & 10 & $\mathrm{Phl}(\mathrm{OAc})_{2}$ & - & $<1 \%$ & ND \\
\hline 2 & 10 & PhlO & - & $<1 \%$ & ND \\
\hline $3^{c}$ & 10 & $\mathrm{PhlO}$ & $\mathrm{Tf}_{2} \mathrm{NH}$ & $35 \%$ & Only $\beta$ \\
\hline $4^{c}$ & 10 & PhlO & $\mathrm{TfOH}$ & $65 \%$ & Only $\beta$ \\
\hline 5 & 10 & PhlO & $\mathrm{Cu}(\mathrm{OTf})_{2}$ & $60 \%$ & Only $\beta$ \\
\hline $6^{d}$ & 10 & $\mathrm{PhlO}$ & $\mathrm{Zn}(\mathrm{OTf})_{2}$ & $86 \%$ e & Only $\beta$ \\
\hline 7 & 10 & $\mathrm{PhlO}$ & AgOTf & $31 \%$ & Only $\beta$ \\
\hline 8 & 10 & $\mathrm{PhlO}$ & $\mathrm{Sc}(\mathrm{OTf})_{3}$ & $80 \%$ & Only $\beta$ \\
\hline 9 & 10 & PhlO & $\mathrm{Zn}\left(\mathrm{NTf}_{2}\right)_{2}$ & $31 \%$ & Only $\beta$ \\
\hline 10 & 24 & $\mathrm{PhlO}$ & $\mathrm{Zn}(\mathrm{OTf})_{2}$ & $<1 \%$ & ND \\
\hline
\end{tabular}

ND not determined

aNMR yield using internal standard $\left(\mathrm{CHBr}_{3}\right)$

based on the ${ }^{1} \mathrm{H}$ NMR analysis of the unpurified reaction mixture

10 mol\% of acid catalyst

$\mathbf{2 5}$ was obtained in $57 \%$ (only $\beta$ ) from the corresponding $\alpha$-stannane using conditions from entry 6

e $83 \%$ isolated yield

aromatic (15), heteroaromatic (17), aliphatic (16, 20), and complex $(18,19)$ ester groups could be installed at the $\mathrm{C1}$ position using the corresponding carboxylic acids in high selectivities. To further probe the generality of this reaction, we applied the optimized conditions from Table 1 to reactions forming anomeric acetates of D-lactose (21), D-arabinose (22), and D-glucosamine (23). The configuration of the anomeric nucleophile has no bearing on the stereochemical outcome of acylation reactions, as demonstrated in the preparation of $\mathbf{1 1}$ and 23, using the $\alpha$ - and $\beta$-anomers, respectively, although the yields of these reactions are slightly diminished.

Having established a general set of conditions for the synthesis of anomeric esters, we next investigated reactions promoting the formation of the glycosidic bond between anomeric nucleophiles and alcohols (Table 2). When 10 was exposed to the optimized conditions from Table 1 using alcoholic solvents $(\mathrm{MeOH}, i$ $\mathrm{PrOH}$, or $\mathrm{CyOH}$ ), acetate $\mathbf{1 1}$ was formed as the only product. In the absence of $\mathrm{CuCl}$, no reaction was observed with 10 using PIDA or PhIO (Table 2, entries 1 and 2). Based on these results, we hypothesized that the transfer of the iodine into the anomeric position could be promoted by a Lewis or Brønsted acid. To test this proposal, $\beta$-D-glucose $\mathbf{1 0}$ was reacted with $\mathrm{PhIO}$ in the presence of catalytic amounts of $\mathrm{Tf}_{2} \mathrm{NH}$ (entry 3 ) or $\mathrm{TfOH}$ (entry 4 ) and the reaction resulted in a clean conversion into glycoside 25 within $12 \mathrm{~h}$ at room temperature.

Further studies revealed the critical role of the catalyst and the oxidant in promoting $O$-glycosylation. We were pleased to find that the combination of $\mathrm{PhIO}$ and $\mathrm{Cu}(\mathrm{OTf})_{2}$ or $\mathrm{Zn}(\mathrm{OTf})_{2}$ (but not $\mathrm{ZnCl}_{2}$ and $\mathrm{ZnBr}_{2}$, entries 5 and 6) promote oxidative reaction with anomeric nucleophiles at room temperature with high $\beta$ selectivity $\left({ }^{1} \mathrm{H}\right.$ NMR). Other stronger oxidants $\left(\mathrm{PhI}(\mathrm{OTf})_{2}\right.$, NFSI, $\mathrm{XeF}_{2}, \mathrm{Br}_{2}, \mathrm{CAN}$, Oxone $\left.{ }^{\circledast}, m-\mathrm{CPBA}\right)$ resulted only in decomposition of the anomeric stannane under a variety of conditions, including those buffered by a bulky base (2,6-di-t-butylpyridine). The presence of a metal triflate is required for the reaction to take place and alkaline metal salts (NaOTf, KOTf) resulted in no reaction (recovered 10) even under forcing conditions $\left(100^{\circ} \mathrm{C}\right.$,
$24 \mathrm{~h})$. Catalyst loadings of $\mathrm{Zn}(\mathrm{OTf})_{2}$ as low as $1 \%$ could promote the conversion of $\mathbf{1 0}$ into 25, although after 2 days the anomeric nucleophile was not fully consumed indicating that the rate of the reaction could be increased by simply adding more catalyst. For practical reasons, however, $5 \mathrm{~mol} \%$ of $\mathrm{Zn}(\mathrm{OTf})_{2}$ was used as the standard conditions for the subsequent studies. Silver and scandium triflates (entries 7 and 8) as well as $\mathrm{Zn}\left(\mathrm{NTf}_{2}\right)_{2}$ (entry 9) are viable catalysts although the yields with these promoters were suboptimal. There is also a negligible effect of temperature on the reaction yield although elevated temperatures $\left(>100^{\circ} \mathrm{C}\right)$ have detrimental effects. Finally, the optimal solvents for this transformation are $\mathrm{CHCl}_{3}$ or aromatic solvents such as $\mathrm{PhMe}$ and benzene. Solvents that are known to participate in the stabilization of the oxonium intermediate (1,4-dioxane, THF, $\mathrm{Et}_{2} \mathrm{O}$, $\mathrm{MeCN})$ result only in low yields $(<10 \%)$. For all conditions tested with 10, exclusive formation of the 1,2-trans anomer 25 was observed even when the a-stannane was used as the substrate, which is in striking contrast to the stereospecific $\mathrm{C}-\mathrm{C}$ bondforming reactions under $\mathrm{Pd}$-catalyzed conditions. Curiously, the presence of a free hydroxyl group at C2 is necessary for the reaction to take place and exposure of the substrate 24 with protected $\mathrm{C} 2-\mathrm{OH}$ position resulted only in the recovery of the stating material (entry 10).

Substrate scope and synthetic applications. The optimized conditions from Table 2 were then applied to reactions with various alcohol acceptors and glycosyl nucleophiles (Fig. 3). We found that the D-glucose stannane $\mathbf{1 0}$ gave consistently high yields and $\beta$ selectivities when reacted with small alcohol nucleophiles (27-31) without the formation of aldehyde or ketone byproducts resulting from oxidation of the alcohols by iodine(III) reagents. Similarly, high yields were recorded for reactions with D-glucose acceptors (32-40), D-galactose (41 and 42), deoxy sugars (42-46), and reactions with disaccharide stannanes (47 and 48). Common protecting groups such as 2-naphthylmethyl (34), para-methoxybenzyl (35), and levulinyl (37) were tolerated and resulted in moderate to excellent yields, providing more options for orthogonal protecting group manipulations for synthesizing complex carbohydrates. To our delight, diacetone-Dglucose, containing the acid-sensitive acetal group, can also be coupled in $86 \%$ yield under the oxidative reaction conditions forming disaccharide 39. In general, glycosyl acceptors equipped with electron-withdrawing groups $(\mathbf{3 6 - 3 8 )}$ are also viable substrates for the oxidative glycosylation without erosion of selectivity. When the reaction was attempted with congested acceptors, we found that a more reactive oxidant (Koser's reagent, $\mathrm{PhI}(\mathrm{OH}) \mathrm{OTs}^{44}$ or $\left.3,5-\left(\mathrm{CF}_{3}\right)_{2} \mathrm{C}_{6} \mathrm{H}_{3} \mathrm{I}(\mathrm{OH}) \mathrm{OTs}\right)^{45}$ gave higher yields than $\mathrm{PhIO}$ and effectively formed glycosides with $\mathrm{C} 4-\mathrm{OH}$ and $\mathrm{C} 2-\mathrm{OH}$ acceptors (49 and 50). We attribute the improved yields with hydroxyiodoaryl reagents to the ease of activation of the iodine and monomeric structures of these oxidants as opposed to the polymeric nature of iodosobenzene. Unlike reactions of partially protected anomeric thioethers ${ }^{5}$, trichloroacetimidates $^{22}$, and glycal epoxides ${ }^{17}$ with hindered glycosyl acceptors that result in a mixture of anomers, oxidative conditions promote exclusive 1,2-trans selectivity without the need for transient protection of the $\mathrm{C} 2$ position.

The oxidative glycosylation is easy to conduct: all substrates are indefinitely stable, the reactions are performed at room temperature, and, due to the significant difference in polarity between the tin by-products and glycosides, purification by column chromatography on silica gel is straightforward and efficient. Furthermore, various technologies are available to remove trace amounts of tin and transition metals ${ }^{46,47}$. 


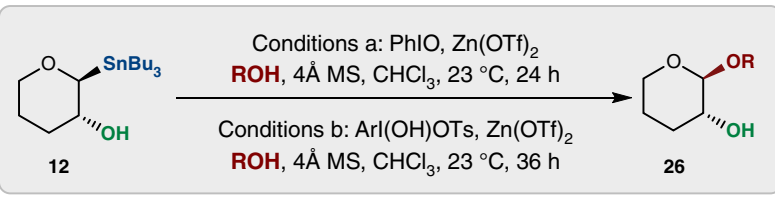

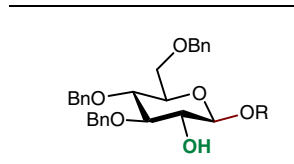

27, $R=M e, 86 \%$

28, $\mathrm{R}=\mathrm{Bn}, 61 \%$

29, $\mathrm{R}=i-\mathrm{Pr}, 76 \%$

30, $R=$ BocSerOMe, $83 \%$

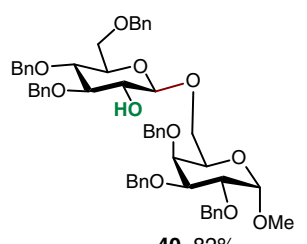

$40,82 \%$

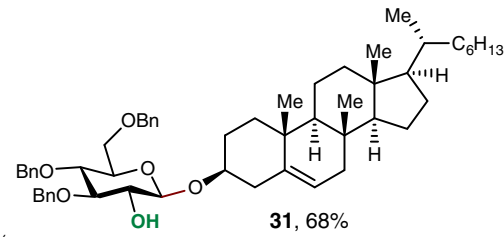

$31,68 \%$

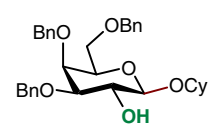

$41,72 \%$

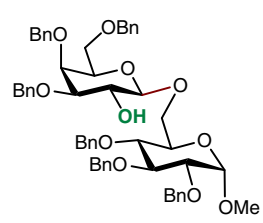

42, $67 \%$

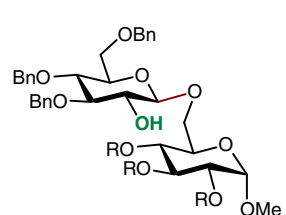

32, $\mathrm{R}=\mathrm{Me}, 80 \%$ 33, $\mathrm{R}=\mathrm{Bn}, \mathbf{8 5} \%$ 34, $\mathrm{R}=\mathrm{Nap}, 78 \%$ $35, R=P M B, 53 \%$

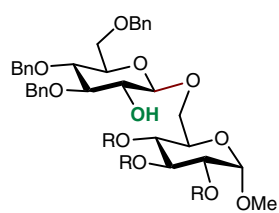

36, $R=A c, 89 \%$ 37, $R=$ Lev, $74 \%$ 38, $R=B z, 60 \%$

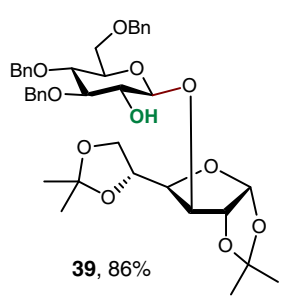

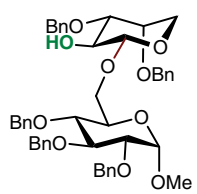

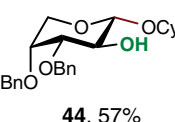

$44,57 \%$

43, $72 \%$
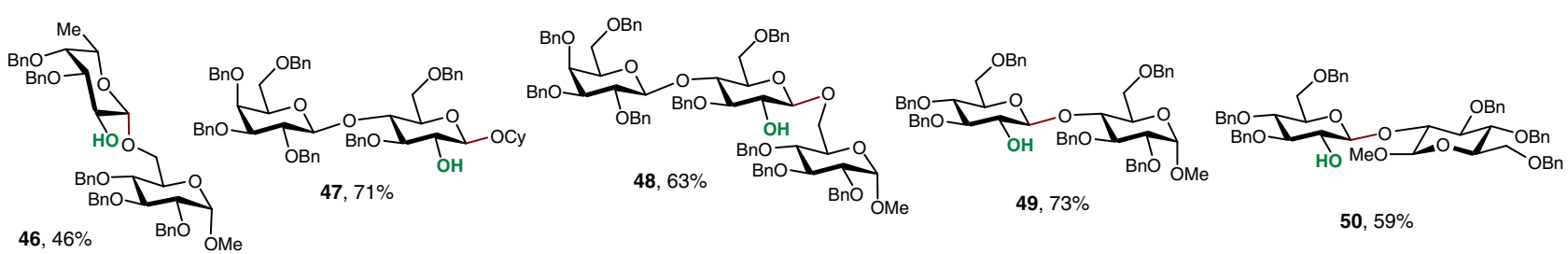

$50,59 \%$

Fig. 3 Scope of oxidative glycosylation with anomeric stannanes. In all cases, only the formation of 1,2-trans anomer was observed (based on the ${ }^{1} \mathrm{H}$ NMR

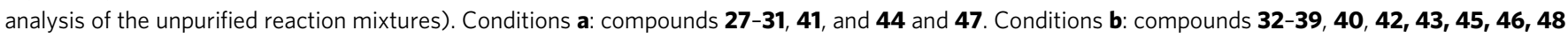
using PhI(OH)OTs and compounds 49 and $\mathbf{5 0}$ using 3,5-( $\left.\mathrm{CF}_{3}\right)_{2} \mathrm{C}_{6} \mathrm{H}_{3} \mathrm{I}(\mathrm{OH}) \mathrm{OTs}$. Compound $\mathbf{3 9}$ required the addition of 2,4,6-tri-tert-butylpyrimidine

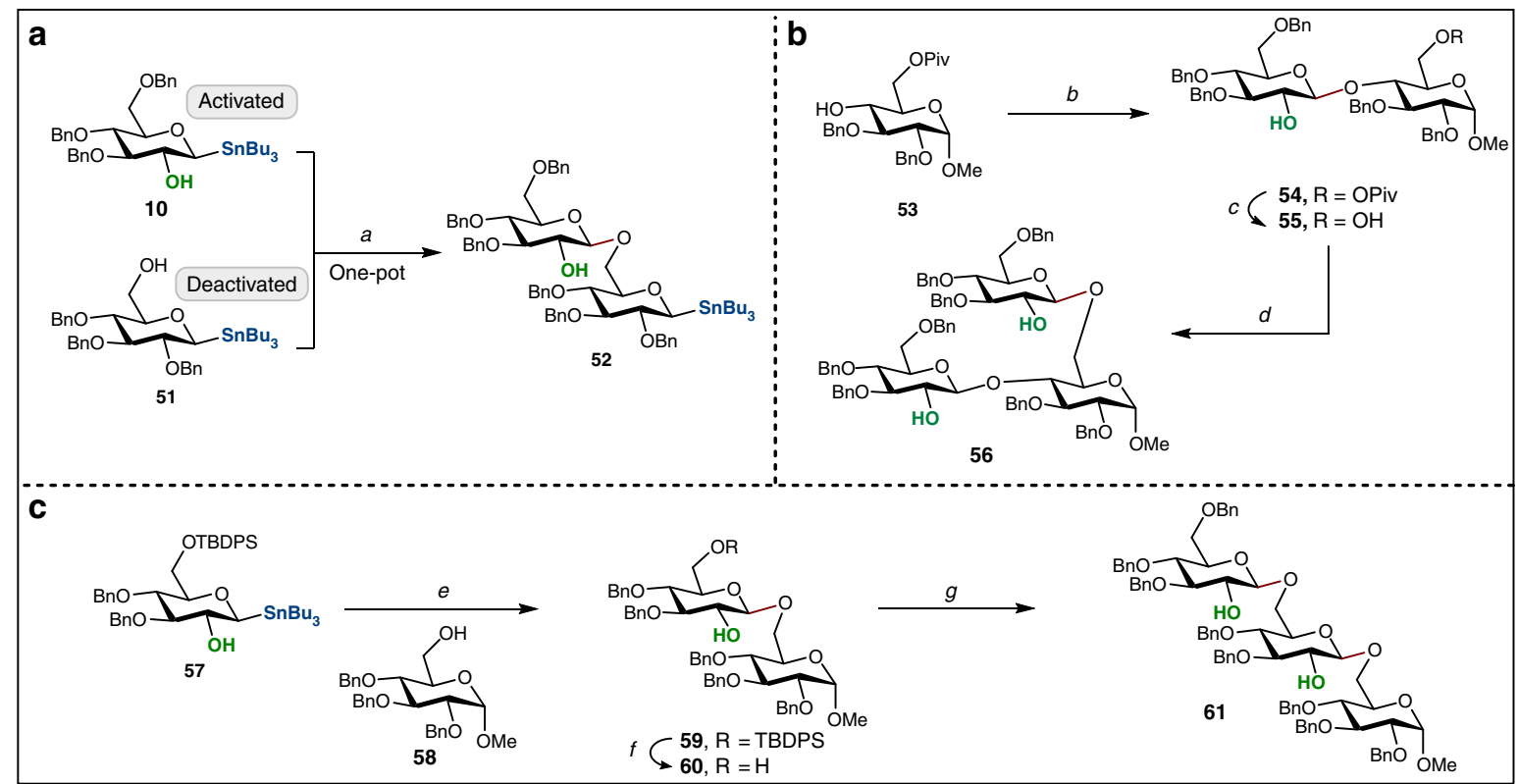

Fig. 4 Orthogonal and sequential glycosylations. a Phl(OH)OTs, $\mathrm{Zn}(\mathrm{OTf})_{2}, \mathrm{CHCl}_{3}, 23^{\circ} \mathrm{C}, 36 \mathrm{~h}, 43 \%$; b 10, $\mathrm{Phl}(\mathrm{OH}) \mathrm{OTs}, \mathrm{Zn}(\mathrm{OTf})_{2}, \mathrm{CHCl}, 23^{\circ} \mathrm{C}, 36 \mathrm{~h}$; c MeONa, $\mathrm{MeOH}, 50{ }^{\circ} \mathrm{C}, 10 \mathrm{~h}, 55 \%$ over two steps; d 10, $\mathrm{Phl}(\mathrm{OH}) \mathrm{OTs}, \mathrm{Zn}(\mathrm{OTf})_{2}, \mathrm{CHCl}_{3}, 23^{\circ} \mathrm{C}, 48 \mathrm{~h}, 56 \%$; e Phl(OH)OTs, $\mathrm{Zn}(\mathrm{OTf})_{2}, \mathrm{CHCl}_{3}, 23^{\circ} \mathrm{C}, 36 \mathrm{~h}$, $82 \%$; f TBAF, THF, $23^{\circ} \mathrm{C}, 24 \mathrm{~h}, 88 \% ; \mathbf{g} \mathbf{1 0}, \mathrm{Phl}(\mathrm{OH}) \mathrm{OTs}, \mathrm{Zn}(\mathrm{OTf})_{2}, \mathrm{CHCl}_{3}, 23^{\circ} \mathrm{C}, 36 \mathrm{~h}, 71 \%$

From the optimization studies, we determined that the a C2coordinating group is necessary for successful $O$-glycosylation. From this observation, we hypothesized that the oxidative protocol could be applied in orthogonal glycosylation with two anomeric nucleophiles in which the free hydroxyl group at C2 activates one nucleophile toward oxidation while the $\mathrm{C} 2$ position in the second anomeric nucleophile is protected thus allowing it to serve as the glycosyl acceptor. To this end, stannanes $\mathbf{5 1}$ and $\mathbf{1 0}$ 


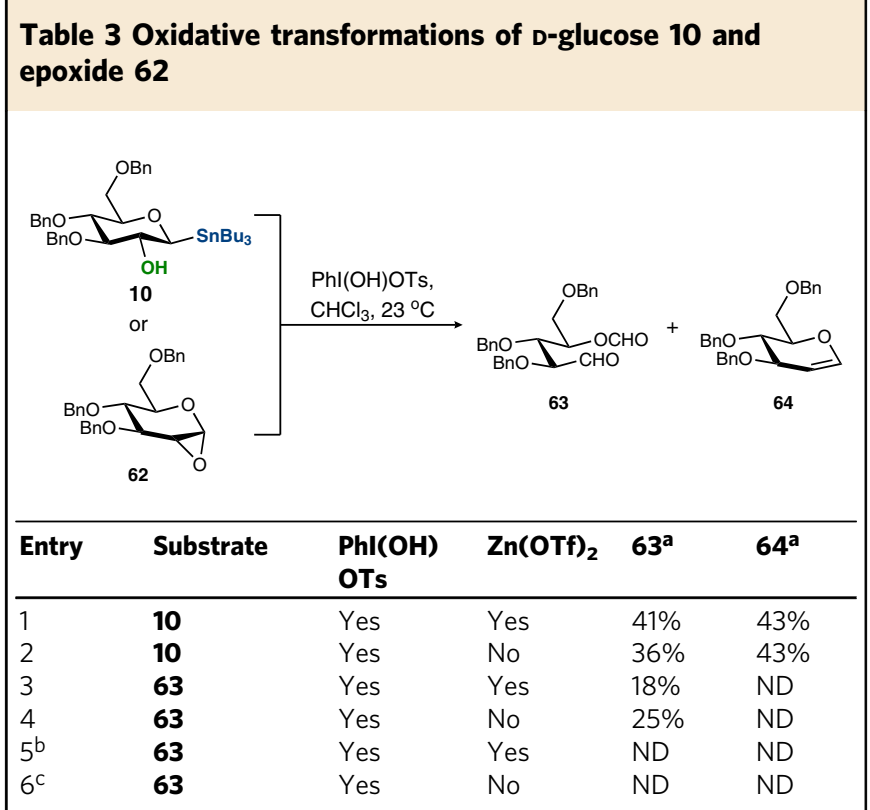

10 or 62 (1 equiv), $\mathrm{Phl}(\mathrm{OH}) \mathrm{OTs}$ ( 1 equiv), $\mathrm{Zn}(\mathrm{OTf})_{2}(5 \mathrm{~mol} \%), \mathrm{CHCl}_{3}(0.05 \mathrm{M}), 23^{\circ} \mathrm{C}, 3-36 \mathrm{~h}$ ND not determined

aNMR yield using internal standard $\left(\mathrm{CHBr}_{3}\right)$

bAs entry 3 with 2 equiv of $\mathrm{CyOH} ; \mathbf{2 5}$ was formed in $51 \%$

As entry 4 with 2 equiv of $\mathrm{CyOH} ; \mathbf{2 5}$ was formed in $53 \%$

were merged under the standard conditions to form saccharide $\mathbf{5 2}$ in $43 \%$ with excellent $\beta$ stereoselectivity with the remainder of the isolated material being D-glucal (Fig. 4a). The sequence of reactions in Fig. 4a represents an example of an orthogonal and sequential union of anomeric nucleophiles based on the activating group at C2. Alternatively, the distinct reactivities of primary and secondary alcohols implies the possibility of chemoselective glycosylation which we demonstrated in the context of sequential glycosylations (Fig. 4b). Thus, the C6-protected glucosyl stannanes 53 and $\mathbf{1 0}$ were joined together under the standard protocol to form disaccharide $\mathbf{5 4}$, followed by deprotection of the pivaloyl ester group. The installation of the third monosaccharide was accomplished in a stereoselective fashion and resulted in the preparation of trisaccharide 56 in 56\% yield. Furthermore, linear trisaccharide $\mathbf{6 1}$ was also obtained with exclusive 1,2-trans selectivity further demonstrating our method's utility in the syntheses of longer oligosaccharides involving minimal protection group operations (Fig. 4c). In contrast to other paradigms in orthogonal glycosylation that capitalize on a combination of thioglycosides and anomeric fluorides or bromides ${ }^{48,49}$, our method features excellent selectivity and milder reaction conditions (e.g., ambient reaction temperatures) which allows for the potential translation of this methodology to the automated assembly of complex oligosaccharides.

Mechanistic investigations. The significant difference in stereochemical outcome between the oxidative glycosylation and that of other transformations affording 1,2-trans pyranosides led us to carry out a series of control experiments summarized in Table 3 and Fig. 5. The following results were obtained: in the absence of an alcohol nucleophile, stannane $\mathbf{1 0}$ was converted into almost equimolar amounts of formate 63 and D-glucal 64 (entries 1 and 2 ). This reaction is independent from the presence of a Lewis acid additive (for details, see Supplementary Figure 1). To investigate the intermediacy of a glycal epoxide in oxidative glycosylation, 62 was treated with Koser's reagent and resulted only in oxidative cleavage product 63 (entries 3 and 4). Since the activating effect of tributyltin ether in $O$-glycosylation was reported by
Danishefsky ${ }^{21}, \mathbf{6 2}$ was treated with $\mathrm{MeOSnBu}_{3}$ (2 equiv) and $\mathrm{Zn}$ $(\mathrm{OTf})_{2}(5 \mathrm{~mol} \%)$ in $\mathrm{CH}_{2} \mathrm{Cl}_{2}$. Although the same stereoselectivity $(\alpha: \beta<1: 99)$ and a slightly diminished yield $(79 \%)$ were observed, the epoxide opening reaction with stannyl ether was significantly slower $(>6 \mathrm{~h}$ ) than the glycosylation with stannane 10 (1 equiv), methanol ( 2 equiv), Koser's reagent (1.2 equiv), and $5 \mathrm{~mol} \%$ of $\mathrm{Zn}$ $(\mathrm{OTf})_{2}$ (<20 $\mathrm{min}, 86 \%$, compound 27$)$. Schmidt reported glycosylation of 2-hydroxy-1-acetimidates resulting in a mixture of anomers $^{22}$. Similar results were reported by Baker in reactions of 2-hydroxy-1-thioglycosides. ${ }^{50}$ To probe the existence of a glycal epoxide, the two reactions described above were monitored with ${ }^{1} \mathrm{H}$ NMR. While $\mathrm{H} 1$ and $\mathrm{H} 2$ in $\mathbf{6 2}$ showed two well-defined peaks and decayed over time, the same signals were absent in the reaction with stannane 10, Koser's reagent, and $\mathrm{Zn}(\mathrm{OTf})_{2}$. In the presence of $\mathrm{CyOH}$ ( 2 equiv) and Koser's reagent, $O$-glycoside 25 was formed in modest yield with no detectable amounts of 63 and 64 (entries 5 and 6). A mechanism involving the oxidative functionalization of glycals via iodoacetoxylation ${ }^{43}$ was excluded on the basis of the reaction of D-glucal $\mathbf{6 4}$ with Koser's reagent and $\mathrm{CyOH}$ resulting in only $8 \%$ of 25 and unidentified compounds. Both $\alpha$ - and $\beta$-stannanes of D-glucose afforded only the 1,2-trans $O$-glycoside 25 regardless of the configuration of the substrate. A reaction of 3,4,6-tri-O-benzyl-D-glucose (a 1,2-diol) with $\mathrm{PhIO}$ or Koser's reagent resulted in oxidative cleavage of the diol and exclusive formation of $\mathbf{6 3}$ indicating that a cyclic $\lambda^{3}$ iodane is not a viable intermediate in the $\mathrm{C}-\mathrm{O}$ bond-forming step $^{16}$. A coordinating group at C2 is necessary for the reaction to take place indicating that the delivery of the oxidant (e.g., ArIO or ArIX $_{2}$ ) into the anomeric position is initiated by a ligand exchange. A reaction of $\mathbf{1 0}$ with Koser's reagent monitored by MS-ESI showed a molecular ion at $\mathrm{m} / z 945.2$ corresponding to protonated iodonium species 65 (Fig. 5a). In the same reaction mixture, tin tosyalte $\mathbf{6 6}$ was also detected (vide infra). Furthermore, exposure of fully protected tetra- $O$-benzyl- $\beta$-D-glucose stannane to $\mathrm{PhIO}$ or Koser's reagent resulted in recovery of the starting material after $24 \mathrm{~h}$ at room temperature. Similar observations were recorded for 2-deoxy-tri- $O$-benzyl- $\beta$-D-glucose stannane suggesting that the steric hindrance at C2 plays a negligible role in initiating the transfer of the iodine group. Lewis or Brønsted acids are necessary for the reaction to take place supporting our initial hypothesis that the hypervalent iodine reagent undergoes activation toward nucleophilic addition and/or substitution.

Further studies were focused on reaction analysis using nuclear magnetic resonance (NMR) spectroscopy to corroborate the identity of reactive intermediates. Treatment of anomeric stannane 10 ( 1 equiv) with Koser's reagent (1.2 equiv) in the presence of a Lewis acid $\left(\mathrm{Zn}(\mathrm{OTf})_{2}, 1\right.$ equiv) was analyzed by lowtemperature NMR $\left(-80\right.$ to $\left.20^{\circ} \mathrm{C}\right)$. The ${ }^{1} \mathrm{H}$ NMR spectra for the reaction mixture revealed a clear doublet at $5.91 \mathrm{ppm}$ and ${ }^{3} J_{(H H)}$ of $3.5 \mathrm{~Hz}$ corresponding to the axial substitution (Fig. $5 \mathrm{~b}$ ). Identical results were observed when $\alpha$-stannane and Koser's reagents were reacted under the same conditions. When the temperature was raised slowly, the characteristic proton signal gradually shifted downfield by $0.05 \mathrm{ppm}$ and disappeared around $0{ }^{\circ} \mathrm{C}$ after $15 \mathrm{~min}$. The use of an analog of Koser's reagent where the iodophenyl group was modified with an electron-withdrawing group $\left(m-\mathrm{CF}_{3}\right)$ resulted in no change in ${ }^{1} \mathrm{H}$ NMR spectra and revealed the formation of the same intermediates as with Koser's reagent. However, exchange of the tosyl group into benzenesulfonate or 2,4-dinitrobenzenesulfonate resulted in the formation of distinct intermediates with an a-configuration at $5.96 \mathrm{ppm}$ $\left({ }^{3} J_{(H H)}=3.6 \mathrm{~Hz}\right)$ and $6.32 \mathrm{ppm}\left({ }^{3} J_{(H H)}=3.4 \mathrm{~Hz}\right)$, respectively. In an independent experiment, we also generated the anomeric triflate of 3,4,6-tri-O-benzyl-D-glucose that showed a distinct peak at $6.38 \mathrm{ppm}\left({ }^{3} J_{(H H)}=3.5 \mathrm{~Hz}\right)$ which was not observed in the 
a

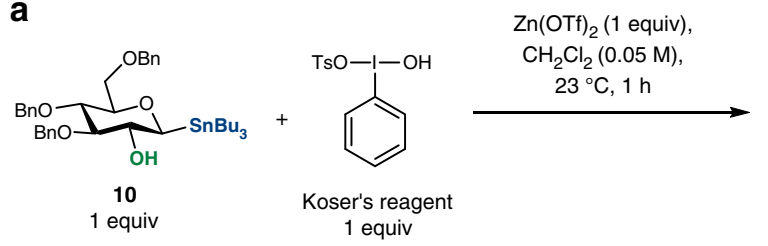

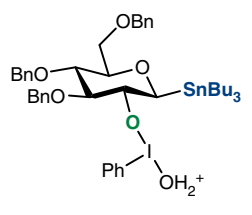

65

Calculated $\mathrm{m} / \mathrm{z}$ : 945.3

Found $m / z$ : 945.2
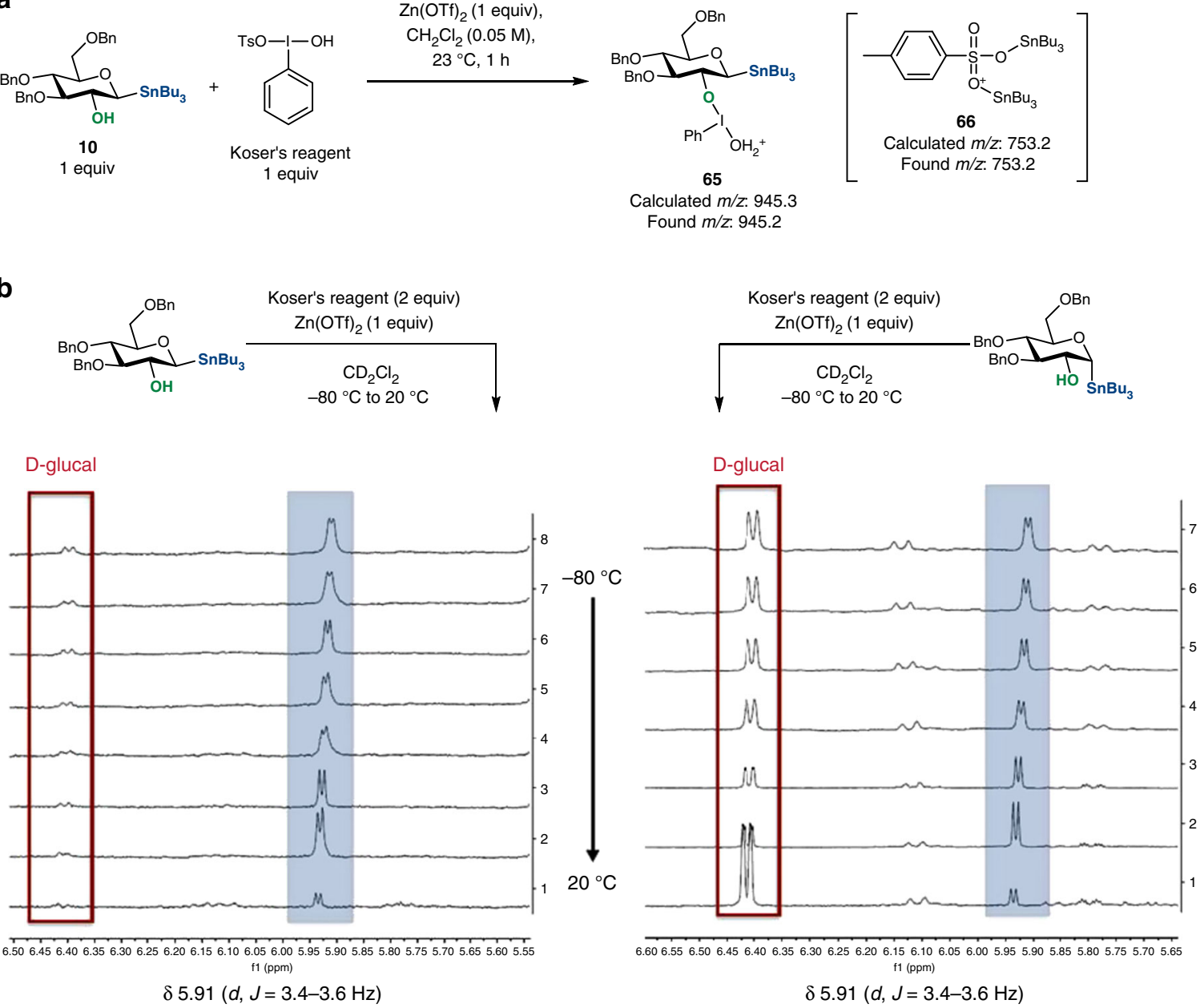

$\delta 5.91(d, J=3.4-3.6 \mathrm{~Hz})$

Fig. 5 Mechanistic investigations. a Reaction of stannane $\mathbf{1 0}$ with Koser's reagent. $\mathbf{b}{ }^{1} \mathrm{H}$ NMR spectra of reaction mixtures of $\alpha$ - and $\beta$-stannanes and Koser's reagent

reactions with Koser's reagent. The similarities of the observed values in reactions with hypervalent iodine to the previously reported data of anomeric $\alpha$-tosylate suggest that the stereochemical determinant in this reaction manifold is an $\alpha$ sulfonate ${ }^{51,52}$. Anomeric tosylates have been shown to undergo $\mathrm{S}_{\mathrm{N}} 2$ reactions with oxygen nucleophiles ${ }^{51}$. These findings are in agreement with the control experiments mentioned above indicating that the $\alpha$-sulfonate is a more reactive species than the glycal epoxide and provides the 1,2-trans stereochemistry in the products.

Taken together, the mechanistic studies suggest that the $\mathrm{C} 2$ hydroxyl group initiates the oxidative glycosylation and modulates the delivery of the hypervalent iodine oxidant. Although the intermediacy of an epoxide cannot be completely excluded at this point, the low yield of $\mathrm{O}$-glycoside $\mathbf{2 5}$ observed in a reaction with 62, exclusive anomeric selectivities for reactions with congested acceptors and with glycosyl donors known to result in a mixture of anomers when reacted in the form of the corresponding epoxides (e.g., galactopyranose), point to an alternative mechanism (Fig. 6). Based on the collected data, we propose that the reaction of $\mathbf{6 7}$ with $\operatorname{ArIO}$ or $\operatorname{ArI}(\mathrm{OH}) \mathrm{OTs}$ is initiated by a ligand exchange between the $\mathrm{C} 2-\mathrm{OH}$ and an iodine reagent ${ }^{53}$. The formation of intermediate $\mathbf{6 8}$ is catalyzed by a Lewis or Brønsted acid that activates ArIO toward addition of an alcohol or facilitates the displacement step at I(III) in the case of Koser's reagent. Given that $\mathrm{PhIO}$ exists as an oligomeric structure, a Lewis acid can also promote depolymerization of

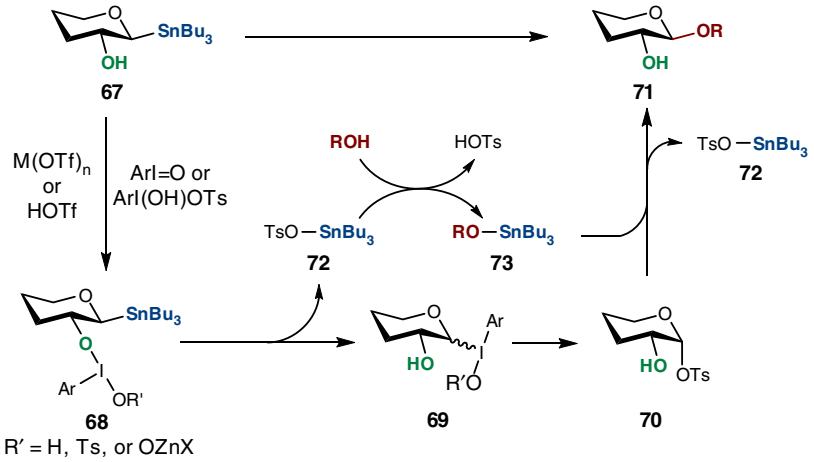

Fig. 6 Mechanistic proposal of oxidative $O$-glycosylation. Plausible reaction mechanism based on experimental investigations

ArIO and catalyze dissolution of the polymeric oxidant. Next, a transfer of iodine into the anomeric position results in the transient formation of intermediate $\mathbf{6 9}$ which, driven by the propensity of iodine to return to its normal valency, undergoes substitution or reductive elimination to generate the $\alpha$-sulfonate 70 (observed experimentally) followed by displacement to yield 71. Solvolysis studies with a vinyl iodonium reagent show that the iodonium moiety is an excellent leaving group with a nucleofugal ability $10^{6}$ higher than the triflate ion (the "IAr(OR')" group functions as a hypernucleofuge $)^{54,55}$. 
Although our initial mechanistic hypothesis for the use of organotin compounds was based on the notion that anomeric stannanes are configurationally stable $\mathrm{C} 1$ nucleophiles, the presence of 66 suggests that the tin group, following its release during the transfer of iodine into the anomeric position, could function to activate the hydroxyl group in the glycosyl acceptor forming nucleophilic ether $\mathbf{7 3}$ that subsequently reacts with $\mathbf{7 0}$. Alternatively, the hydroxyl group in glycosyl donor 67 could be activated with tin thus promoting a ligand exchange at the iodine atom of the oxidant. Taken together, the combination of tributyltin-activated glycosyl acceptor and the formation of an a-tosylate lead to high anomeric selectivities of the glycosylation reactions surveyed under the oxidative conditions.

\section{Discussion}

Here, we show an oxidative $O$-glycosylation reaction involving anomeric nucleophiles with alcohols and carboxylic acids resulting in exclusive anomeric selectivities. These reactions require a $\mathrm{C} 2$-coordinating group and open possibilities for the development of preparative oligosaccharide protocols capitalizing on orthogonal activation modes of anomeric nucleophiles with minimal protective group manipulations. Furthermore, this method can serve as a complementary tool to classical O-glycosylation protocols and, given its mild conditions and ambient reaction temperatures, can be easily adapted to suit the needs of automated synthetic strategies.

\section{Methods}

Materials. For ${ }^{1} \mathrm{H},{ }^{13} \mathrm{C}$ NMR spectra of compounds in this manuscript, see Supplementary Information. For detailed synthetic procedures, see Supplementary Information.

General procedures. General procedure for anomeric acylation: Under $\mathrm{N}_{2}$, a onedram vial was charged with anomeric stannane $(0.100 \mathrm{mmol})$, phenyliodonium biscarboxylate $(0.200 \mathrm{mmol}), \mathrm{CuCl}(0.200 \mathrm{mmol}), \mathrm{KF}(0.400 \mathrm{mmol})$, freshly activated powdered $4 \AA \mathrm{MS}$ (ca. $100 \mathrm{mg})$, anhydrous toluene $(1.00 \mathrm{~mL})$ and anhydrous 1,4-dioxane $(1.00 \mathrm{~mL})$ and was heated up to $110^{\circ} \mathrm{C}$. The reaction was stirred for 12 $\mathrm{h}$, and filtered through Celite ${ }^{\boxplus}$. The filtrate was concentrated and purified by column chromatography on $\mathrm{SiO}_{2}$.

General procedure for glycosylation with iodosobenzene: Under $\mathrm{N}_{2}$, anomeric stannane $(0.100 \mathrm{mmol}-0.200 \mathrm{mmol})$, the corresponding alcohol $(0.100-0.200$ $\mathrm{mmol}), \mathrm{Zn}(\mathrm{OTf})_{2}(0.010-0.100 \mathrm{mmol})$, iodosobenzene $(0.200-0.300 \mathrm{mmol})$, freshly activated $4 \AA \mathrm{MS}$ and anhydrous $\mathrm{CHCl}_{3}(0.50-2.00 \mathrm{~mL})$ were successively added into a vial. The reaction mixture was stirred at room temperature for the indicated period of time, filtered through a pad of silica gel, and concentrated. ${ }^{1} \mathrm{H}$ NMR spectra were recorded using this mixture to evaluate diastereoselectivity. The crude material was purified by column chromatography on $\mathrm{SiO}_{2}$.

General procedure for glycosylation with hydroxy(tosyloxy)iodobenzene (Koser's reagent): Under $\mathrm{N}_{2}$, anomeric stannane $(0.100 \mathrm{mmol})$, the corresponding alcohol $(0.100 \mathrm{mmol}), \mathrm{Zn}(\mathrm{OTf})_{2}(0.005 \mathrm{mmol})$, hydroxy(tosyloxy)iodobenzene $(0.100 \mathrm{mmol})$, freshly activated $4 \AA \mathrm{MS}$, and anhydrous $\mathrm{CH}_{2} \mathrm{Cl}_{2}(4.00 \mathrm{~mL})$ were successively added into a vial. After stirring at room temperature for $12 \mathrm{~h}$, anomeric stannane $(0.100 \mathrm{mmol})$ and hydroxy(tosyloxy)iodobenzene $(0.100 \mathrm{mmol})$ were added and stirred for additional $12 \mathrm{~h}$, and this procedure was repeated one more time. The reaction mixture was filtered through a pad of silica gel, and concentrated. ${ }^{1} \mathrm{H}$ NMR spectra were recorded using this mixture to evaluate diastereoselectivity. The crude material was purified by column chromatography on $\mathrm{SiO}_{2}$

\section{Data availability}

All relevant data are available upon request from the authors.

Received: 12 February 2018 Accepted: 3 August 2018

Published online: 07 September 2018

\section{References}

1. Varki, A. et al. Essentials of Glycobiology (Cold Spring Harbor Laboratory Press, Cold Spring Harbor, NY, 2009).
2. Gabius, H.-J. The Sugar Code: Fundamentals of Glycosciences (WileyBlackwell, Weinheim, Germany, 2009).

3. Frihed, T. G., Bols, M. \& Pedersen, C. M. Mechanisms of glycosylation reactions studied by low-temperature nuclear magnetic resonance. Chem. Rev. 115, 4963-5013 (2015).

4. Mamidyala, S. K. \& Finn, M. G. Glycosylation using unprotected alkynyl donors. J. Org. Chem. 74, 8417-8420 (2009).

5. Du, Y. G., Gu, G. F., Wei, G. H., Hua, Y. X. \& Linhardt, R. J. Synthesis of Saponins using partially protected glycosyl donors. Org. Lett. 5, 3627-3630 (2003).

6. Halcomb, R. L. \& Danishefsky, S. J. On the direct epoxidation of glycalsapplication of a reiterative strategy for the synthesis of $\beta$-linked oligosaccharides. J. Am. Chem. Soc. 111, 6661-6666 (1989).

7. Yu, B. A. \& Sun, J. S. Glycosylation with glycosyl Nphenyltrifluoroacetimidates (PTFAI) and a perspective of the future development of new glycosylation methods. Chem. Commun. 46, 4668-4679 (2010).

8. Codee, J. D. C., Litjens, R. E. J. N., van den Bos, L. J., Overkleeft, H. S. \& van der Marel, G. A. Thioglycosides in sequential glycosylation strategies. Chem. Soc. Rev. 34, 769-782 (2005).

9. Trumtel, M., Tavecchia, P., Veyrieres, A. \& Sinaÿ, P. The synthesis of 2'deoxy- $\beta$-disaccharides-novel approaches. Carbohydr. Res. 191, 29-52 (1989).

10. Kristensen, S. K., Salamone, S., Rasmussen, M. R., Marqvorsen, M. H. S., \& Jensen, H. H. Glycosyl ortho-methoxybenzoates: catalytically activated glycosyl donors with an easily removable and recyclable leaving group. Eur. J. Org. Chem. 32, 5365-5376 (2016).

11. Li, Y. L., Mo, H. P., Lian, G. Y. \& Yu, B. Revisit of the phenol O-glycosylation with glycosyl imidates, $\mathrm{BF}_{3} \cdot \mathrm{OEt}_{2}$ is a better catalyst than TMSOTf. Carbohydr. Res. 363, 14-22 (2012).

12. Crich, D. \& Xu, H. D. Direct stereocontrolled synthesis of 3-amino-3-deoxy- $\beta$ mannopyranosides: importance of the nitrogen protecting group on stereoselectivity. J. Org. Chem. 72, 5183-5192 (2007).

13. Manabe, S., Ishii, K., Hashizume, D., Koshino, H. \& Ito, Y. Evidence for endocyclic cleavage of conformationally restricted glycopyranosides. Chem. Eur. J. 15, 6894-6901 (2009).

14. Benakli, K., Zha, C. X. \& Kerns, R. J. Oxazolidinone protected 2-amino-2deoxy-D-glucose derivatives as versatile intermediates in stereoselective oligosaccharide synthesis and the formation of $\alpha$-linked glycosides. J. Am. Chem. Soc. 123, 9461-9462 (2001).

15. Huang, M. et al. Dissecting the mechanisms of a class of chemical glycosylation using primary ${ }^{13} \mathrm{C}$ kinetic isotope effects. Nat. Chem. 4, 663-667 (2012).

16. Kim, J. Y., Di Bussolo, V. \& Gin, D. Y. Stereoselective synthesis of 2-hydroxya-mannopyranosides from glucal donors. Org. Lett. 3, 303-306 (2001).

17. Li, Y., Tang, P., Chen, Y. \& Yu, B. Gold(I)-catalyzed glycosidation of 1,2anhydrosugars. J. Org. Chem. 73, 4323-4325 (2008).

18. Honda, E. \& Gin, D. Y. C2-hydroxyglycosylation with glycal donors. Probing the mechanism of sulfonium-mediated oxygen transfer to glycal enol ethers. $J$. Am. Chem. Soc. 124, 7343-7352 (2002).

19. Di Bussolo, V., Kim, Y.-J. \& Gin, D. Y. Direct oxidative glycosylations with glycal donors. J. Am. Chem. Soc. 120, 13515-13516 (1998).

20. Gervay, J., Peterson, J. M., Oriyama, T. \& Danishefsky, S. J. An unexpected sialylation: total syntheses of ganglioside GM4 and a positional isomer. J. Org Chem. 58, 5465-5468 (1993).

21. Randolph, J. T. \& Danishefsky, S. J. First synthesis of a digitalis saponin. Demonstration of the scope and limitations of a convergent scheme for branched oligosaccharide synthesis by the logic of glycal assembly. J. Am. Chem. Soc. 117, 5693-5700 (1995).

22. Cinget, F. \& Schmidt, R. R. Synthesis of unprotected O-glycosyl trichloroacetimidates and their reactivity towards some glycosyl acceptors. Synlett 1993, 168-170 (1993).

23. Padungros, P., Alberch, L. \& Wei, A. Glycosyl dithiocarbamates: $\beta$-selective couplings without auxiliary groups. J. Org. Chem. 79, 2611-2624 (2014).

24. Padungros, P., Alberch, L. \& Wei, A. Glycal assembly by the in situ generation of glycosyl dithiocarbamates. Org. Lett. 14, 3380-3383 (2012).

25. Plante, O. J., Palmacci, E. R., Andrade, R. B. \& Seeberger, P. H. Oligosaccharide synthesis with glycosyl phosphate and dithiophosphate triesters as glycosylating agents. J. Am. Chem. Soc. 123, 9545-9554 (2001).

26. Nakanishi, M., Takahashi, D. \& Toshima, K. Light-induced O-glycosylation of unprotected deoxythioglycosyl donors. Org. Biomol. Chem. 11, 5079-5082 (2013).

27. Hoang, Le. Mai et al. A minimalist approach to stereoselective glycosylation with unprotected donors. Nat. Commun. 8, 1146 (2017).

28. Pelletier, G., Zwicker, A., Allen, C. L., Schepartz, A. \& Miller, S. J. Aqueous glycosylation of unprotected sucrose employing glycosyl fluorides in the presence of calcium ion and trimethylamine. J. Am. Chem. Soc. 138 , 3175-3182 (2016) 
29. Park, Y. et al. Macrocyclic bis-thioureas catalyze stereospecific glycosylation reactions. Science 355, 162-166 (2017).

30. Chan, D. M. T., Monaco, K. L., Wang, R.-P. \& Winters, M. P. New N- and Oarylations with phenylboronic acids and cupric acetate. Tetrahedron Lett. 39, 2933-2936 (1998).

31. Lam, P. Y. S. et al. New aryl/heteroaryl C-N bond cross-coupling reactions via arylboronic acid/cupric acetate arylation. Tetrahedron Lett. 39, 2941-2944 (1998).

32. Evans, D. A., Katz, J. L. \& West, T. R. Synthesis of diaryl ethers through the copper-promoted arylation of phenols with arylboronic acids. An expedient synththesis of thyroxine. Tetrahedron Lett. 39, 2937-2940 (1998).

33. González, I., Mosquera, J., Guerrero, C., Rodríguez, R. \& Cruces, J. Selective monomethylation of anilines by $\mathrm{Cu}(\mathrm{OAc})_{2}$-promoted cross-coupling with $\mathrm{MeB}(\mathrm{OH})_{2}$. Org. Lett. 11, 1677-1680 (2009).

34. Sueki, S. \& Kuninobu, Y. Copper-catalyzed N- and O-alkylation of amines and phenols using alkylborane reagents. Org. Lett. 15, 1544-1547 (2013).

35. Rossi, S. A., Shimkin, K. W., Xu, Q., Mori-Quiroz, L. M. \& Watson, D. A. Selective formation of secondary amides via the copper-catalyzed crosscoupling of alkylboronic acids with primary amides. Org. Lett. 15, 2314-2317 (2013).

36. Mori-Quiroz, L. M., Shimkin, K. W., Rezazadeh, S., Kozlowski, R. A. \& Watson, D. A. Copper-catalyzed amidation of primary and secondary alkyl boronic esters. Chem. Eur. J. 22, 15654-15658 (2016).

37. El Khatib, M. \& Molander, G. A. Copper(II)-mediated O-arylation of protected serines and threonines. Org. Lett. 16, 4944-4947 (2014).

38. Quach, T. D. \& Batey, R. A. Copper(II)-catalyzed ether synthesis from aliphatic alcohols and potassium organotrifluoroborate salts. Org. Lett. 5, 1381-1384 (2003).

39. Zhu, F., Rourke, M. J., Yang, T., Rodriguez, J. \& Walczak, M. A. Highly stereospecific cross-coupling reactions of anomeric stannanes for the synthesis of C-aryl glycosides. J. Am. Chem. Soc. 138, 12049-12052 (2016).

40. Zhu, F. et al. Glycosyl cross-coupling of anomeric nucleophiles-scope, mechanism and applications in the synthesis of aryl C-glycosides. J. Am. Chem. Soc. 139, 17908-17922 (2017).

41. Ochiai, M., Fujita, E., Arimoto, M. \& Yamaguchi, H. Iodine (III)-mediated allylation of aromatic compounds and alcohols using allylmetal (Group IVb) compounds. Chem. Pharm. Bull. 33, 41-47 (1985).

42. Yoshimura, A. \& Zhdankin, V. V. Advances in synthetic applications of hypervalent iodine compounds. Chem. Rev. 116, 3328-3435 (2016)

43. Shi, L., Kim, Y.-J. \& Gin, D. Y. C2-acyloxyglycosylation with glycal donors. J. Am. Chem. Soc. 123, 6939-6940 (2001).

44. Koser, G. F., Wettach, R. H., Troup, J. M. \& Frenz, B. A. Hypervalent organoiodine. Crystal structure of phenylhydroxytosyloxyiodine J. Org. Chem. 41, 3609-3611 (1976).

45. Nabana, T. \& Togo, H. Reactivities of novel [hydroxy(tosyloxy)iodo] arenes and [hydroxy(phosphoryloxy)iodo] arenes for $\alpha$-tosyloxylation and $\alpha$ phosphoryloxylation of ketones. J. Org. Chem. 67, 4362-4365 (2002).

46. Miyamoto, H. et al. Effective method to remove metal elements from pharmaceutical intermediates with polychelated resin scavenger. Org. Proc. Res. Dev. 19, 1054-1061 (2015).

47. Le Grognec, E., Chrétien, J.-M., Zammattio, F. \& Quintard, J.-P. Methodologies limiting or avoiding contamination by organotin residues in organic synthesis. Chem. Rev. 115, 10207-10260 (2015).

48. Kanie, O., Ito, Y. \& Ogawa, T. Orthogonal glycosylation strategy in oligosaccharide synthesis. J. Am. Chem. Soc. 116, 12073-12074 (1994).

49. Ito, Y., Kanie, O. \& Ogawa, T. Orthogonal glycosylation strategy for rapid assembly of oligosaccharides on a polymer support. Angew. Chem. Int. Ed. Engl. 35, 2510-2512 (1996).

50. Meng, B., Zhu, Z. \& Baker, D. C. 1,2-cis alkyl glycosides: straightforward glycosylation from unprotected 1-thioglycosyl donors. Org. Biomol. Chem. 12, 5182-5191 (2014)
51. Issa, J. P. \& Bennett, C. S. A reagent-controlled $\mathrm{S}_{\mathrm{N}} 2$-glycosylation for the direct synthesis of $\beta$-linked 2-deoxy-sugars. J. Am. Chem. Soc. 136, 5740-5744 (2014).

52. Bohé, L. \& Crich, D. Selective Glycosylations: Synthetic Methods and Catalysts (Wiley-VCH Verlag, Weinheim, Germany, 2017).

53. Ray, D. G. \& Koser, G. F. Iodinanes with iodine(III)-bound homochiral alkoxy ligands: preparation and utility for the synthesis of alkoxysulfonium salts and chiral sulfoxides. J. Am. Chem. Soc. 112, 5672-5673 (1990).

54. Okuyama, T., Takino, T., Sueda, T. \& Ochiai, M. Solvolysis of cyclohexenyliodonium salt, a new precursor for the vinyl cation: remarkable nucleofugality of the phenyliodonio group and evidence for internal return from an intimate ion-molecule pair. J. Am. Chem. Soc. 117, 3360-3367 (1995)

55. Ochiai, M. Hypervalent iodine chemistry. Top. Curr. Chem. 224, 6 (2003).

\section{Acknowledgements}

This work was supported by the University of Colorado at Boulder and the $\mathrm{NIH}$ (GM125284). Mass spectral analyses were recorded at the University of Colorado Boulder Central Analytical Laboratory Mass Spectrometry Core Facility (partially funded by the NIH, RR026641).

\section{Author contributions}

T.Y. developed the method, performed the experiments on the oxidative acylation and glycosylation of anomeric stannanes, and conducted the spectroscopic studies. F.Z. performed the experiments on the oxidative glycosylation of anomeric stannanes and mechanistic studies. M.A.W. conceived the study and supervised the experimental work. All authors participated in the design of the study and interpretation of the results. M.A. W. wrote the manuscript with contributions from all authors. All authors have read and approved the final version of the manuscript.

\section{Additional information}

Supplementary Information accompanies this paper at https://doi.org/10.1038/s41467018-06016-4.

Competing interests: The authors declare no competing interests.

Reprints and permission information is available online at http://npg.nature.com/ reprintsandpermissions/

Publisher's note: Springer Nature remains neutral with regard to jurisdictional claims in published maps and institutional affiliations.

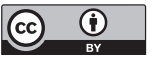

Open Access This article is licensed under a Creative Commons Attribution 4.0 International License, which permits use, sharing, adaptation, distribution and reproduction in any medium or format, as long as you give appropriate credit to the original author(s) and the source, provide a link to the Creative Commons license, and indicate if changes were made. The images or other third party material in this article are included in the article's Creative Commons license, unless indicated otherwise in a credit line to the material. If material is not included in the article's Creative Commons license and your intended use is not permitted by statutory regulation or exceeds the permitted use, you will need to obtain permission directly from the copyright holder. To view a copy of this license, visit http://creativecommons.org/ licenses/by/4.0/.

(C) The Author(s) 2018 